\title{
Ectopic breast cancer: A case report
}

\author{
Safa Önel, Faruk Karateke, Adnan Kuvvetli, Sefa Özyazıcı, Mehmet Özdoğan
}

\section{ABSTRACT}

Department of General Surgery

Adana Numune Teaching

Hospital, Adana, Turkey

\section{Address for Correspondence}

\section{Dr. Faruk Karateke}

Department of General Surgery, Adana Numune Teaching Hospital, Adana, Turkey Phone.: +905321629290

e-mail:

karatekefaruk@hotmail.com

Received: 27.02 .2012

Accepted: 05.08 .2012

Online Available Date: 28.05.2013

(C) Copyright 2013 by Turkish Surgical Association
Ectopic breast may be present at any site, from the axilla to the vulva, other than its normal location. Cysts, adenofibromas and rarely carcinomas have been reported in ectopic breasts. In this case report, we present a patient with ectopic breast cancer. The patient had a thickening and enlarging of her ectopic breast tissue, on the left arcus costarium. Tru-cut biopsy revealed "invasive lobular carcinoma". Left ectopic mastectomy and level I-II axillary dissection were performed and then chemotherapy+radiotherapy+endocrine therapy treatment was commenced. During follow up, the patient is doing well; in spite of R1 resection, she has no evidence of local recurrences or distant metastases.

Key Words: Ectopic breast cancer, accessory breast, ectopic mastectomy

\section{INTRODUCTION}

Ectopic breast can be seen anywhere on the milk line from the axilla to the vulva, as a result of noncomplete normal embryological development of the breast bud. Familial transmission might be seen and breast cancer development has also been rarely reported. In this article we present a case in whom surgery was performed for an ectopic breast cancer.

\section{CASE PRESENTATION}

Forty-one -year-old female patient presented complaining of a mass under her left breast, dark brownish discoloration and a tense feeling around this area for the last 7-8 months, on August 2010. Her bilateral breast and right axilla examinations were normal, a $2 \times 2 \mathrm{~cm}$ hard, mobile lymph node was observed in the left axilla. The left ectopic breast was located anterior to the costal arch, its surrounding skin showed dark brownish discoloration, and a firm subcutaneous mass of $2 \times 2 \mathrm{~cm}$ was palpable (Figure 1).

The breasts were bilaterally normal on mammography. The breast ultrasonography (US) showed both breasts to be normal, but an ectopic breast was reported at the inferior of the left breast. Tru-cut biopsy was performed from the ectopic breast, which revealed "invasive lobular carcinoma". The patient's abdominal sonography, thoracoabdominal computed tomography and whole-body bone scintigraphy were within normal limits. This case was staged as T4N1M0 and "left ectopic mastectomy+level I-II axillary dissection" was applied (Figure 2a, b).

The pathological examination of the mastectomy and axillary dissection specimen revealed residual tumor deposits in the posterior surface of the mastectomy material. Also lymphovascular invasion $(+)$, ER 100\%+, PR 100\% +, c-erb B2: + and lymph node metastasis in 4/12 were determined.

The patient was referred to Medical Oncology and Radiation Oncology departments. She received radiotherapy (RT), chemotherapy (CT) and endocrine therapy (ET), and is still being followed-up with no local recurrence and distant metastases.

\section{DISCUSSION}

Ectopic (accessory) breast can be seen anywhere on the milk line from the axilla to the vulva, as a result of non-complete normal embryological development of the breast bud (1). It is more common than amastia. It has gained attention in history beginning from the early ages, the statue of Ephesian Diana is symbolic with her 20 ectopic breasts (2). Ectopic breast can be seen in three ways. 1-Numerous nipples 2- Numerous nipple-areola complex 3- Numerous breast.

The rate of ectopic breast is $1-4 \%$ in Caucasians. This abnormality is more common in the Far East. It can be seen in both sexes. There is familial transmission. Its incidence is reported as $1.68 \%$ in Japanese men, 
and as $5.19 \%$ in Japanese women $(2,3)$. These abnormal structures are most often located in the axilla, followed by the area immediately inferior to the normal breast. This abnormality is detected on both sides in about $50 \%$ of cases $(2,3)$. In addition to these areas its location in the acromial or scapular region, vulva, in the midline of thorax and abdomen have also been rarely reported $(2,4)$. Ectopic breasts enlarge during pregnancy and lactation, they may lactate if they have a normal ductal system. Articles stating that infants were breastfed from ectopic breasts are also present (2). Adenofibroma, cysts, and carcinomas have also been reported in ectopic breasts containing glandular breast parenchyma, as in normal breast tissue. Carcinomas are reported to be rare $(1,2,5,6)$. Although carcinoma within the ectopic breast tissue is rare, ductal, lobular, medullary, mucinous, papillary, and invasive secretory (juvenile ) carcinomas have been reported $(1,4,6)$. In its treatment, wide excision , level I-Il axillary dissection + radiotherapy (RT) + chemotherapy $(\mathrm{CT})+$ endocrine-hormone therapy (ET) was performed (1, 5-7).

We applied ectopic mastectomy + level I-II axillary dissection to our patient. In ectopic mastectomy, lower and upper flaps were prepared as in standart mastectomy. Because the underlying
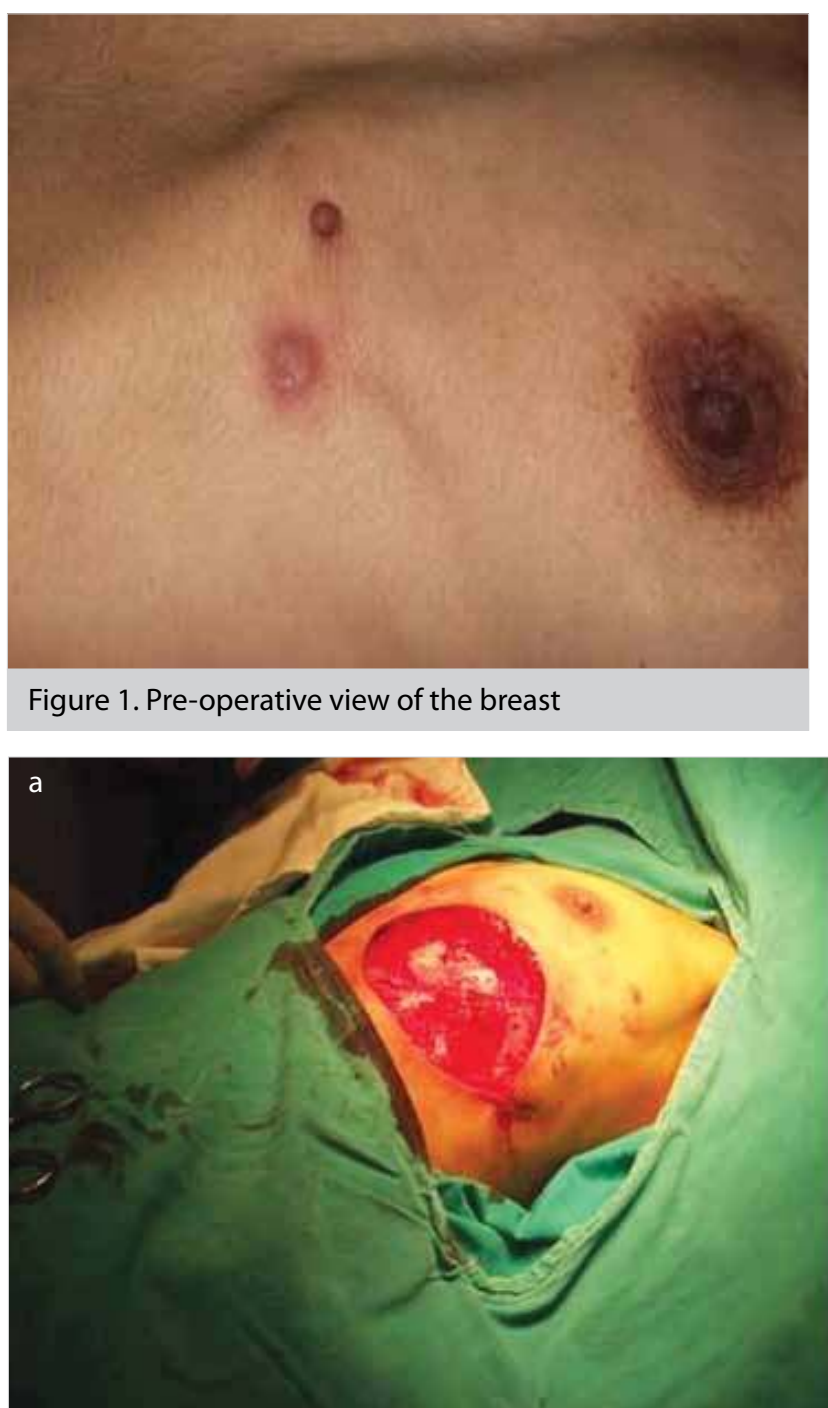

Figure $2 \mathrm{a}, \mathrm{b}$. Post-operative view of the breast muscle tissue was very thin, a wide-deep excision extending down to the ribs was performed. The axillary dissection was performed from a separate axillary incision (Figure 2b).

Our surgical procedure is consistent with the literature $(1,5,6)$. However, in the literature, the term "Ectopic Mastectomy" does not exist. We used this terminology because we believe that it completely defines this surgery.

Despite the fact that ectopic mastectomy extended deep down to the ribs, the posterior surface of the mastectomy material contained residual carcinoma. We think that besides the patient's thin body stature, the absence of a thick muscle layer behind the ectopic breast tissue and the late stage of the disease all contributed to this adverse condition. A CT + RT + ET was planned for the patient after surgery. Four cycles of adjuvant cyclophosphamide $600 \mathrm{mg} / \mathrm{m}^{2}$ and doxorubicin $60 \mathrm{mg} /$ $\mathrm{m}^{2}$ was given followed by paclitaxel $80 \mathrm{mg} / \mathrm{m}^{2}$ after 12 weeks. Radiotherapy at 50 Grays was planned for lymph node positivity. The treatment was completed with $3.6 \mathrm{mg}$ of goserelin and tamoxifen $20 \mathrm{mg} /$ day, and she is still in complete remission. This management plan is also consistent with the literature $(1,5-7)$.

\section{CONCLUSION}

Data regarding local recurrence and survival in patients with ectopic breast cancer could not be obtained due to its rare incidence. As the number of reported cases increases and records of these patients is held in a diligent manner, it will be possible to access relevant information.

Author Contributions: Concept - F.K., S.Ö.; Design - F.K., S.Ö.; Data Collection and/or Processing - S.Ö., A.K.; Analysis and/or Interpretation M.Ö., S.Ö.; Writer - S.Ö., F.K.

Peer-review: Externally peer-reviewed.

Conflict of Interest: No conflict of interest was declared by the authors.

Financial Disclosure: The authors declared that this study has received no financial support.

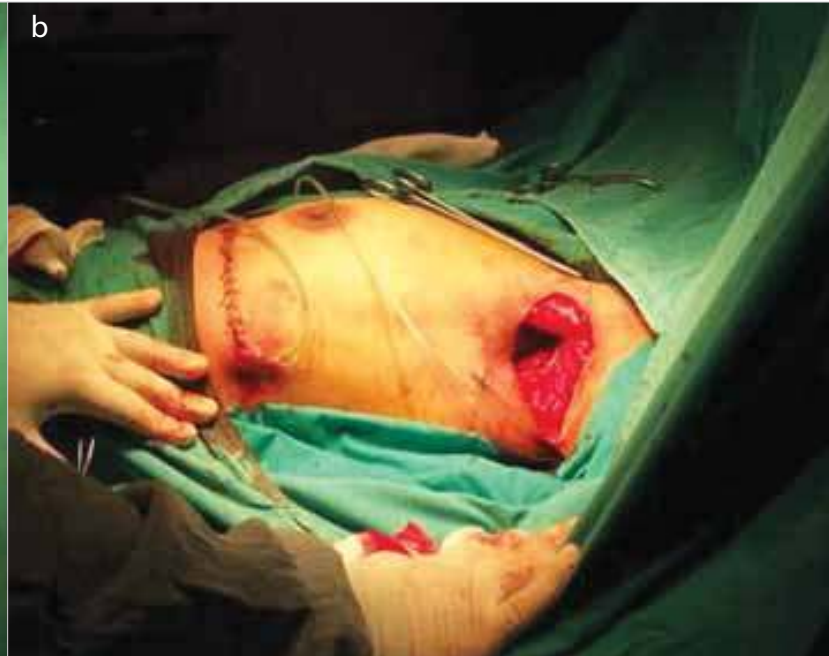


Önel et al.

Ectopic breast cancer

\section{REFERENCES}

1. Shin SJ, Sheikh FS, Allenby PA, Rosen PP. Invasive secretory (juvenile) carcinoma arising in ectopic breast tissue of the axilla. Arch Pathol Lab Med 2001; 125: 1372-1374.

2. Haagensen CD. Anatomy of the mammary gland. In Diseases of the breast. WB Saunders Company.2nd ed.Rev. reprint. Philadelphia1971;4-9.

3. Greig D, Garden JO, Breast. In: Colour Atlas of Surgical Diagnosis. Mosby\&Wolf 2nd Ed. Barcelona, 1996; 24-36.

4. Chung-Park M, Zheng C, Ciampioli EJ, Emery JD. Mucinous adenocarcinoma of ectopic breast tissueof the vulva. Arc Pathol Lab Med 2002; 126: 1216-1218.
5. Avilés Izquierdo JA, Martínez Sánchez D, Suárez Fernandez R, Lázaro Ochaita P, Longo-Imedio MI. Pigmented axillary nodule: carcinoma of an ectopic axillary breast. Dermatol Surg 2005; 31: 237-239. [CrossRef]

6. Pardo M, Silva F, Jimenez P, Karmelic M. Mammary carcinoma in an ectopic breast tissue: A case report. Rev Med Chil 2001; 129: 663665.

7. Visconti G, Elthair Y, VanGinkel RJ, Werker PM. Approach and management of primary ectopic breast carcinoma in the axilla:where are we?A comprehensive historical literature review. J Plast Reconsr Aesthet Surg 2011; 64: 1-11. [CrossRef] 